\title{
ENHANCEMENT OF THERAPEUTIC WINDOW OF METFORMIN HYDROCHLORIDE BY FABRICATION OF MICROSPHERES COMPRISING POLYMERIC INCULCATION WITH SEMI- SYNTHETIC AND SYNTHETIC POLYMERS BY IMPLEMENTATION OF BOX-BEHNKEN DESIGN
}

\author{
MD AAMER QUAZI ${ }^{1}$, NAZIA KHANAM ${ }^{2,3^{*}}$
}

${ }^{1}$ K. T. Patil College of Pharmacy, Osmanabad, Maharashtra, India, ${ }^{2}$ Research Scholar, Faculty of Science and Technology (Pharmacy), Dr. Babasaheb Ambedkar Marathwada University, Aurangabad, Maharashtra, India., ${ }^{3}$ Malla Reddy Institute of Pharmaceutical Sciences, Hyderabad, Telangana State, India

*Email: nazia.khanam7@gmail.com

Received: 25 Feb 2021, Revised and Accepted: 28 May 2021

\begin{abstract}
Objective: Innovative enhancement of therapeutic window of Metformin hydrochloride (MFH) and bioavailability through mucoadhesive microspheres by polymeric inculcation of hydroxypropyl methylcellulose K4M grade (HPMC K4M), hydroxypropyl methylcellulose K100M grade (HPMC K100M) and Kollidon SR grade (KS).

Methods: Controlled release system was developed by incorporating semi-synthetic and synthetic polymers by modified solvent evaporation technique. Fabrication of mucoadhesive microspheres was designed by the implementation of experimental designs to obtain most optimum concentration of selected factors. The method was optimized by Box Behnken design (BBD) with selected factors as concentrations of semisynthetic and synthetic polymer with stirring speed influence for the obtained responses that were mean particle size (Y1) entrapment efficiency of drug (Y2) and percent mucoadhesion (Y3). Microspheres were characterized for particle size, entrapment efficiency of drug, ex-vivo mucoadhesion study, in vitro study, Fourier transform infrared spectroscopy (FTIR), x-ray diffraction (XRD) detection and $\mathrm{H}^{1} \mathrm{Nuclear}$ magnetic resonance (NMR) quantification for optimized formulation.
\end{abstract}

Results: Implementation of response surface method software for BBD yielded stable microspheres with mean particle size $274 \mu \mathrm{m}$, entrapment efficiency of drug $85.07 \%$ and percent mucoadhesion $67.03 \%$ for optimized formulation F5.

Conclusion: Bridging of MFH with the highly innovative combination of semi-synthetic and synthetic polymers yielded stable, cost-effective microspheres with improved bioavailability with controlled-release effect as till date no literature is available that provide information with selected polymeric combination and analytical characterization.

Keywords: Box-behnken design, Controlled release system, Kollidon SR, Metformin hydrochloride, Nuclear magnetic resonance

(C) 2021 The Authors. Published by Innovare Academic Sciences Pvt Ltd. This is an open access article under the CC BY license (https://creativecommons.org/licenses/by/4.0/) DOI: https://dx.doi.org/10.22159/ijap.2021v13i4.41225. Journal homepage: https://innovareacademics.in/journals/index.php/ijap

\section{INTRODUCTION}

Selection of drug is the most optimum parameter in designing of a particular dosage form. In our research, we had focused on such a drug that has multivariate effect with minimum side effects. MFH was selected as a model drug in present research work. MFH is the most felicitously picked alternative in treatment of non-insulin dependent diabetes mellitus (NIDDM. It is an orally administered, anti-hyperglycemic biguanide drug [1-4]. MFH has numerous other applications in drug therapy including emendation of menstrual cycles by making them more regular and enhances fertility in women. It is also used in patients with polycystic ovarian syndrome (PCOS) [5, 6]. It has anti-tumor effect on colon, ovaries, pancreas, breast and lungs cancer cells, hence, it has strong anti-proliferative effect [7], possesses anti-oxidant activity, shows high efficacy in diabetic nephropathy [8]. Several research articles revealed that MFH also exhibits good cardiovascular protective effect that was independent of its glucose lowering efficacy $[9,10]$. There are some minor side effects including stomach pain, nausea, vomiting, diarrhea, muscle pain with major adverse effect includes ketoacidosis, hence the drug should be prohibited to patients with impaired kidney functioning due to occurrence of lactic acid acidosis, and otherwise it is the first line treatment drug in patients associated with diabetes mellitus either alone or in combination with other glucose-lowering drugs [11]. MHF is a biguanide white to off-white compound having molecular weight 165.63 and molecular formula $\mathrm{C}_{4} \mathrm{H}_{11} \mathrm{~N}_{5} \cdot \mathrm{HCl}$ (Imido dicarbo nimidic diamide, $\mathrm{N}, \mathrm{N}$ dimethyl-,monohydrochloride; 1,1-Dimethylbiguanide mono hydro chloride) with absolute bioavailability of $50-60 \%$ and plasma halflife of $1.5 \mathrm{~h}$ to $4.5 \mathrm{~h}$, the therapeutic window of MFH in plasma lies between 01 and $50 \mu \mathrm{M}$ [12]. On oral administration, there exists an incomplete gastrointestinal absorption of MFH with absolute bioavailability of 40 to $60 \%$ and rapid elimination, hence the administration of a controlled release (CR) formulation of MFH would be beneficial to maintain the optimum therapeutic window of drug and minimize dosing frequency due to short half-life so enhanced patient acceptability will be obtained [13]. In this research we had tried to develop a polymeric inculcation of semi-synthetic and synthetic polymers for CR of MFH by microspheres fabrication. The semi-synthetic polymer selected was HPMC, also known as hypromellose, it is one of the best known semi-synthetic non-ionic cellulosic, biocompatible and viscoelastic polymer with unique property of high water absorption and retention capacity. There were several grades of hypromellose available, the composition differs due the substitution of methyl and hydroxyl propyl group present in the structure [14]. The selected HPMC grades in our research comprised of HPMC K4M and HPMC K100M as synthetic polymers in fabrication of CR formulation of MFH. The combination of both grades had been opted as they yielded high swellability, as soon as they encounters with water or simulated gastric fluid they develop a viscous gel layer and results in CR of drug from HPMC matrices. HPMC K4M has strong mucoadhesive property whereas HPMC K100M has high gastro-retentive nature $[15,16]$. The another desirably chosen polymer for our research was KS, it comes under the category of synthetic polymer, the sustaining capacity of drug in matrix formulation makes $\mathrm{KS}$ an ideal candidate in fabrication of $\mathrm{CR}$ formulations along with improved bioavailability $[17,18]$. As our focus in this research was to enhance the therapeutic window of MFH through incorporating the drug with semi-synthetic and synthetic polymeric inculcations of matrix yielding CR of drug, we tried to design mucoadhesive microspheres of MFH to increase the residence time of formulation in the stomach. The narrow therapeutic window and short half-life of MFH make it a suitable candidate to be designed as mucoadhesive microspheres for 
enhancement of therapeutic index, improved bioavailability and reduced side effects [19]. The interpenetration of polymer molecules to mucosal membrane was higher with low molecular weight polymers whereas with higher molecular weight entanglement will be obtained, hence a combination of low and high molecular weight polymers were selected to obtain improved effect $[20,21]$. So, in our research we had selected different grades of HPMC as opted semisynthetic polymer to obtain good mucoadhesive, gastro-retentive (GR) and CR effect along with enhanced CR effect of KS as the synthetic polymer for fabrication of MFH loaded mucoadhesive microspheres. Literature revealed numerous research and review articles on MFH, in one study performed by Karna S et al., 2016, they had prepared GR, swellable and floating sustained release tablets. They had fabricated the tablet formulation by incorporating HPMC, xanthan gum, sodium alginate, carbopol and ethyl cellulose. The prepared formulation was also found to be stable for tenure of three months [22]. The study conducted by Quazi M A et al., 2020, revealed formulation of MFH loaded microspheres comprising of natural and synthetic polymer for comparative analysis. The result revealed enhanced flow properties with higher drug entrapment efficiency for microspheres fabricated with synthetic polymer Carbopol as compared with formulation designed with natural polymer sodium alginate [23]. The present research study involved fabrication and characterization of MFH microspheres inculcating semi-synthetic and synthetic polymers by employing response surface methodology and implementing Box-Behnken design (BBD). BBD was selected from the ocean of various available experimental designs and applied to statistically optimize the formulation to improve therapeutic index and bioavailability of drug by enhancement of entrapment efficiency and CR of MFH in this study. The selected variables were HPMC K4M concentration (A), HPMC K100M concentration (B) Kollidon SR concentration (C) and stirring speed (D) along with selected response variables as mean particle size (Y1) percent entrapment efficiency (Y2) and percent mucoadhesion (Y3) of fabricated microspheres with predetermined level values for these variables estimated by trails according to factorial design $[24,25]$. The selected method is highly innovative, especially the optimization of formulation parameters by following response surface method as till date there does not exists any literature reporting mucoadhesive microspheres of $\mathrm{MFH}$ with combination of HPMC K4M, HPMC K100M and KS fabricated by modified solvent evaporation technique. This makes our research work highly novel and discrete from the available literature with characterization of optimized formulation by latest modern analytical techniques incorporating estimation of particle size, entrapment efficiency of drug, percentage mucoadhesion, in vitro drug release profile, drug polymer interaction analysis by FTIR physical state estimation of drug by XRD detection and NMR based quantification.

\section{MATERIALS AND METHODS}

\section{Chemicals and reagents}

Metformin hydrochloride was obtained as a gift sample from Aurobindo Pharmaceuticals Ltd, Hyderabad, India, HPMC K4M and HPMC K 100M were received from S D fine chemicals, Mumbai, India, Kollidon SR was purchased from Natco, Hyderabad, India, All other chemicals used were of analytical grade reagent.

\section{Method of fabrication}

Fabrication of MFH loaded microspheres comprising of semisynthetic and synthetic polymers were produced by contemporaneous application of solvent evaporation and diffusion techniques. Initially, as per the data obtained from RSM software by using $\mathrm{BBD}$, the specified parameters were recorded and employed in microspheres formulation for seven batches from F1 to F7 by following ED. Initially, accurately weighed quantities of MFH, HPMC K4M, HPMC K100M, KS and $0.1 \%$ polyethylene glycol were mixed in 1:1 mixture of dichloromethane and ethanol at room temperature. Then the above mentioned slurry was slowly introduced to $80 \mathrm{ml}$ of $0.46 \%(\mathrm{~W} / \mathrm{V})$ polyvinyl alcohol (emulsifier). The system was stirred for three hours by using Remi Lab Magnetic stirrer with speed meter to remove the volatile solvent ethanol at room temperature to produce spherical microspheres. The microspheres were collected by vacuum filtration and washed repeatedly with water. Finally, the prepared microspheres were dried at ambient temperature $\left(25^{\circ} \mathrm{C}\right)$ for $24 \mathrm{~h}$ and dried in vacuum chamber at $25^{\circ} \mathrm{C}$ for $2 \mathrm{~h}$ to remove any residual solvent. All the process variables like concentration of HPMC K4M, concentration of HPMC K100M, concentration of KS and stirring speed were studied during optimization of microspheres and the most optimum concentration with maximum stabilized formulation was recorded as seen in table 2 .

\section{Experimental design (ED)}

The present research of formulating and characterizing CR microspheres of MFH was mainly focused to improve the therapeutic index of drug by improving bioavailability and residence time of drug within body, as it is drug candidate that comes under the category of comprising low therapeutic window. Design and fabrication was statistically optimized by BBD for various formulation parameters like, maximum drug entrapment efficiency of microspheres and mean particle size. This research was executed by optimization of MFH microspheres through response surface methodology by applying BBD and using Design Expert 12.0.7.0 software (STATEASE Inc., USA), with quadratic design model that yielded 27 experimental runs for present data [26, 27].

\section{Characterization of MFH loaded mucoadhesive microspheres} through semi-synthetic and synthetic polymers

\section{Particle size estimation}

MFH loaded microspheres were accurately determined by optical microscopic method using calibrated stage micrometer.

\section{Entrapment efficiency of drug}

The quantity of pure MFH loaded in fabricated microspheres was investigated by taking $100 \mathrm{mg}$ of prepared formulation in $50 \mathrm{ml}$ of phosphate buffer $(\mathrm{pH}=7.4)$ in volumetric flask then kept on sonicator at $125 \mathrm{~W}$ (Imeco sonofier, Imco ultrasonics, India) for two hours to mix uniformly, finally the volume was made up to $100 \mathrm{ml}$ by adding buffer, then again this flask was kept on sonicator for one hour and kept as it is overnight for extraction of drug from microspheres. Then the solution was passed through $0.45 \mu \mathrm{m}$ membrane filter to collect the filtrate. The respective dilutions were made from this stock solution and absorbance was measured at 233 $\mathrm{nm}$ employing UV-visible spectrophotometer (UV-2450 Shimadzu, Japan) against blank. The method was repeated three times.

\section{Ex-vivo mucoadhesive study}

The mucoadhesive property of fabricated MFH loaded microspheres were evaluated by taking freshly excised piece of goat stomach mucosa and then they were mounted on glass slides with the help of cyanoacrylate glue and 50 prepared microspheres were spread on the wet rinsed tissue specimen with 4 drops of $0.01 \mathrm{~N} \mathrm{HCl}$ and immediately the slides were hung to the arm of USP tablet disintegration test apparatus with the help of suitable support. Then the disintegration test machine was operated and the attached mucosal specimen was given regular up and down movement in the fluid comprising $800 \mathrm{ml} 0.01 \mathrm{~N} \mathrm{HCl}(\mathrm{pH}=2.0)$ at $37 \pm 0.5{ }^{\circ} \mathrm{C}$ in one liter vessel capacity for various time interval up to $7 \mathrm{~h}$. Then the apparatus was stopped and the number of adhered microspheres to the mucosal tissue were counted $[28,29]$.

\section{In vitro drug release analysis}

The release of MFH drug from the prepared microspheres was studied in $0.1 \mathrm{~N} \mathrm{HCl}$ at $\mathrm{pH} 1.2$ and in phosphate buffer $\mathrm{pH} 7.4(900$ $\mathrm{ml}$ ) respectively using a USP six station dissolution (LAB DISSO 2000) rate testing apparatus with a rotating paddle at $50 \mathrm{rpm}$ and $25 \mathrm{~cm}$ depth 20 by maintaining temperature of $37 \pm 0.5^{\circ} \mathrm{C}$. Sample of $5 \mathrm{ml}$ was withdrawn at various time intervals and subsequently diluted using $\mathrm{pH} 7.4$ phosphate buffer. After suitable dilutions the absorbance was measured at $206 \mathrm{~nm}$ for $0.1 \mathrm{~N} \mathrm{HCl}$ and $233 \mathrm{~nm}$ for phosphate buffer, using UV-visible spectrophotometer (2450 Shimadzu, Japan) against a blank. The withdrawn sample was filtered through Whatman grade 1 filter paper and diluted to estimate $\mathrm{MFH}$ at $233 \mathrm{~nm}$ through spectroscopy against blank solution. The quantity of drug was estimated through calibration 
curve and release studies were performed in triplicate and the observed data represented in table 6.

\section{FTIR analysis}

The detection of any possible interaction between pure drug and optimized formulation of MFH loaded microspheres were scanned through FTIR spectra by using Perkin-Elmer FTIR (spectrum RX).

\section{XRD study}

XRD analysis was performed to determine the crystalline characteristic of drug and optimized fabricated microspheres by using X-ray diffractometer (Brucker Axs, 08 Advance) [30].

\section{NMR analysis}

The compatibility analysis of fabricated MFH microspheres with incorporated polymers was performed by using proton $\left(\mathrm{H}^{1}\right)$ Nuclear magnetic resonance spectroscope (ECX 400 JOEL, Japan) working at $500 \mathrm{MHz}$ and $300 \mathrm{~K}$ with dimethy sulphoxide (DMSO-d6) as solvent for estimation of chemical shift in this experiment.

\section{RESULTS AND DISCUSSION}

The present statistically optimized and BBD assisted MFH loaded microspheres were fabricated by employing optimized parameters as represented in table 1 and table 2 . The fabrication method was

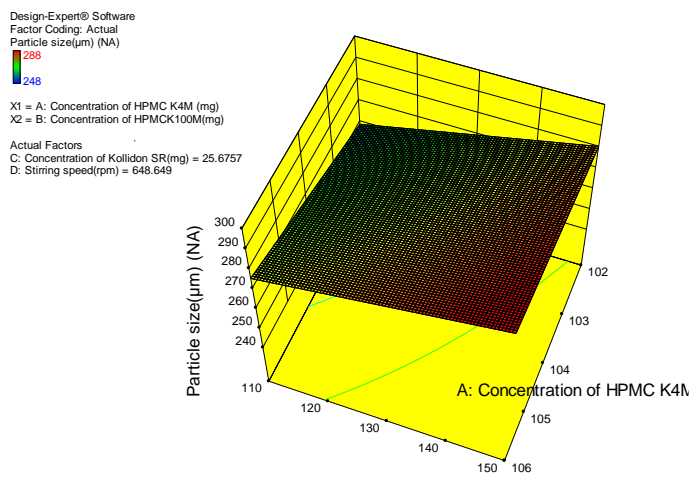

B: Concentration of HPMCK100M(mg) (NA)
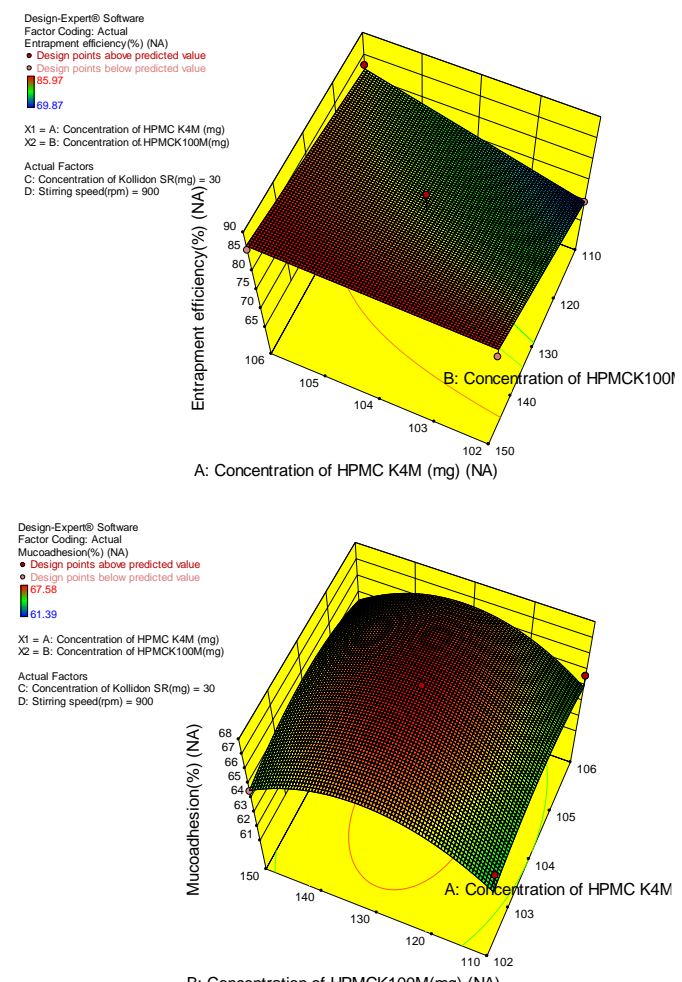

experimentally designed and the data obtained from design for factors $\mathrm{A}, \mathrm{B}$ and $\mathrm{C}$ with their corresponding responses $\mathrm{Y} 1, \mathrm{Y} 2$ and $\mathrm{Y} 3$ were explained through fig. 1 and fig. 2 with the corresponding values represented in table 1 and table 2. Finally, analysis of variance (ANOVA) was applied to obtain significant difference from design matrix and the data obtained after implementation of ANOVA was represented in table 3 , table 4 and table 5 and were found to be significant. The data obtained from experimental design for factors $\mathrm{A}, \mathrm{B}$ and $\mathrm{C}$ with their corresponding responses $\mathrm{Y} 1, \mathrm{Y} 2$ and $\mathrm{Y} 3$ were explained through fig. 1 and 2.

\section{Particle size analysis}

It was observed from the obtained data that mean particle size of MFH loaded microspheres ranged between $246.01 \pm 0.49 \mu \mathrm{m}$ to $289.13 \pm 0.07$ $\mu \mathrm{m}$ for all fabricated formulations, whereas in one study executed by Kesharwani S et al., 2020 [31] they had fabricated MFH microspheres incorporating eudragit and HPMC with particle size range $397 \pm 23.22$ $\mu \mathrm{m}$ to $595 \pm 15.82 \mu \mathrm{m}$ and entrapment efficiency ranged from $(83.49 \pm 1.33) \%$ to $(60.02 \pm 1.65) \%$. On implementation of BBD to the parameter mean particle size yielded superior microspheres with spherical surface, smaller particle size and microsphere size increased on increasing polymer concentration for all the seven formulations. The mean particle size of $274 \mu \mathrm{m}$ for F5 formulation was obtained with maximum optimization.
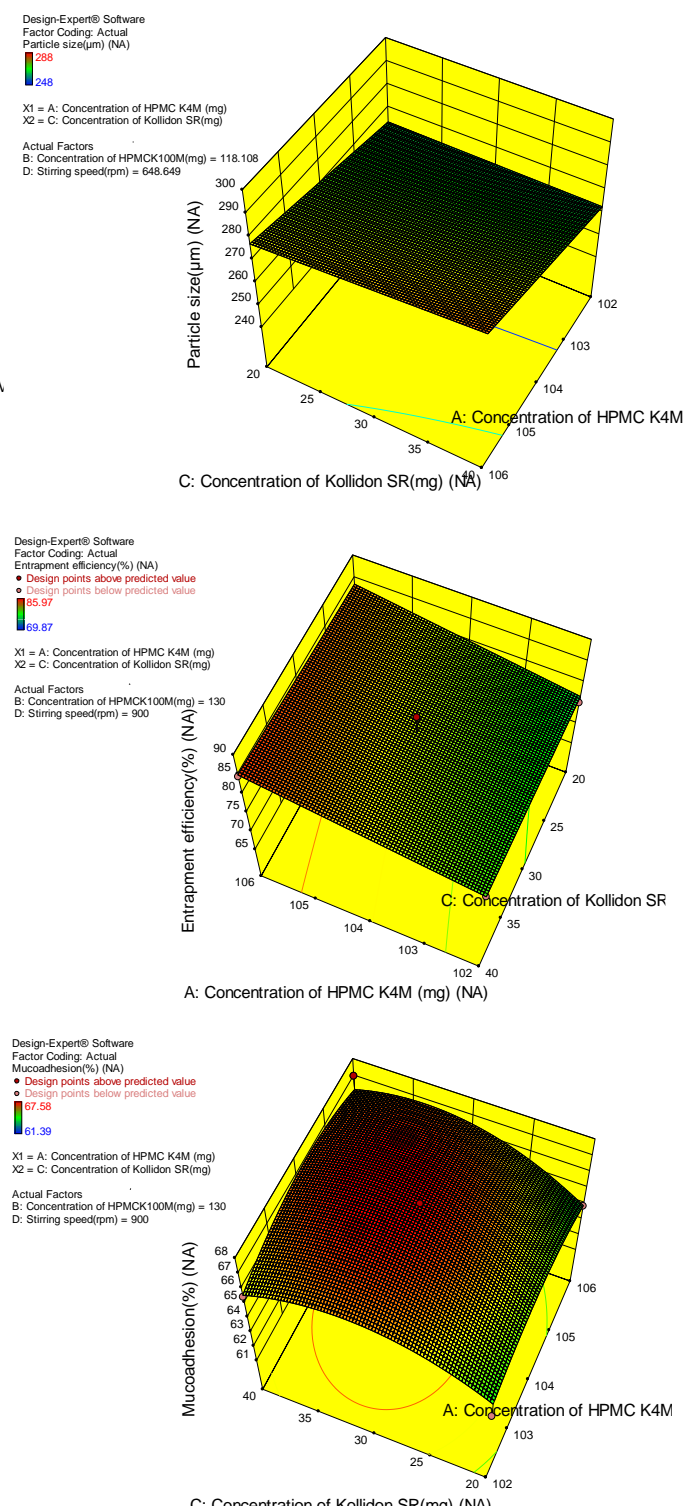

C: Concentration of Kollidon SR(mg) (NA)

Fig. 1: Three dimensional response surface effects from factors A, B and C with their corresponding responses Y1, Y2 and Y3 
Khanam et al.

Table 1: Data representing optimized fabrication parameters and investigated range during microspheres formulation

\begin{tabular}{|c|c|c|c|c|c|c|c|c|}
\hline Factor & Name & Units & Minimum & Maximum & Low level & High level & Mean & Standard deviation \\
\hline A & Concentration of HPMC K4M & $\mathrm{mg}$ & 102.00 & 106.00 & $-1 \leftrightarrow 102.00$ & $+1 \leftrightarrow 106.00$ & 104.00 & 01.35 \\
\hline B & Concentration of HPMC K100M & $\mathrm{mg}$ & 110.00 & 150.00 & $-1 \leftrightarrow 110.00$ & $+1 \leftrightarrow 150.00$ & 130.00 & 13.58 \\
\hline $\mathrm{C}$ & Concentration of KS & $\mathrm{mg}$ & 020.00 & 40.00 & $-1 \leftrightarrow 20.00$ & $+1 \leftrightarrow 40.00$ & 030.00 & 06.79 \\
\hline $\mathrm{D}$ & Stirring speed & $\mathrm{rpm}$ & 600.00 & 1200.00 & $-1 \leftrightarrow 600.00$ & $+1 \leftrightarrow 1200.00$ & 900.00 & 203.81 \\
\hline
\end{tabular}

*mean \pm SD (Standard deviation), $\mathrm{n}=3$

Table 2: Data representing Box-Behnken experimental design layout with selected factors and obtained responses

\begin{tabular}{|c|c|c|c|c|c|c|c|c|}
\hline Std & Run & Factor 1 & Factor 2 & Factor 3 & Factor 4 & Response Y1 & Response Y2 & Response Y3 \\
\hline 4 & 1 & 106 & 150 & 30 & 900 & 279 & 85.73 & 64.08 \\
\hline 10 & 2 & 106 & 130 & 30 & 600 & 283 & 83.65 & 64.31 \\
\hline 25 & 3 & 104 & 130 & 30 & 900 & 272 & 84.97 & 67.58 \\
\hline 23 & 4 & 104 & 110 & 30 & 1200 & 248 & 73.94 & 61.39 \\
\hline 9 & 5 & 102 & 130 & 30 & 600 & 267 & 78.04 & 65.27 \\
\hline 16 & 6 & 104 & 150 & 40 & 900 & 288 & 85.03 & 63.06 \\
\hline 14 & 7 & 104 & 150 & 20 & 900 & 281 & 84.93 & 64.71 \\
\hline 27 & 8 & 104 & 130 & 30 & 900 & 272 & 84.97 & 67.58 \\
\hline 1 & 9 & 102 & 110 & 30 & 900 & 259 & 69.87 & 65.28 \\
\hline 15 & 10 & 104 & 110 & 40 & 900 & 266 & 72.07 & 64.15 \\
\hline 17 & 11 & 102 & 130 & 20 & 900 & 263 & 75.38 & 63.74 \\
\hline 24 & 12 & 104 & 150 & 30 & 1200 & 264 & 85.97 & 64.03 \\
\hline 3 & 13 & 102 & 150 & 30 & 900 & 271 & 84.08 & 64.61 \\
\hline 12 & 14 & 106 & 130 & 30 & 1200 & 279 & 83.85 & 65.04 \\
\hline 11 & 15 & 102 & 130 & 30 & 1200 & 258 & 77.43 & 64.91 \\
\hline 19 & 16 & 102 & 130 & 40 & 900 & 263 & 79.08 & 65.52 \\
\hline 13 & 17 & 104 & 110 & 20 & 900 & 257 & 72.94 & 62.47 \\
\hline 26 & 18 & 104 & 130 & 30 & 900 & 272 & 84.97 & 67.58 \\
\hline 2 & 19 & 106 & 110 & 30 & 900 & 274 & 83.06 & 64.72 \\
\hline 22 & 20 & 104 & 150 & 30 & 600 & 284 & 85.02 & 65.53 \\
\hline 8 & 21 & 104 & 130 & 40 & 1200 & 279 & 85.07 & 66.17 \\
\hline 5 & 22 & 104 & 130 & 20 & 600 & 283 & 83.09 & 64.72 \\
\hline 18 & 23 & 106 & 130 & 20 & 900 & 280 & 81.85 & 63.94 \\
\hline 21 & 24 & 104 & 110 & 30 & 600 & 265 & 77.03 & 64.21 \\
\hline 6 & 25 & 104 & 130 & 40 & 600 & 287 & 85.04 & 66.32 \\
\hline 7 & 26 & 104 & 130 & 20 & 1200 & 261 & 82.41 & 62.83 \\
\hline 20 & 27 & 106 & 130 & 40 & 900 & 287 & 84.67 & 67.03 \\
\hline
\end{tabular}

${ }^{*}$ mean \pm SD (Standard deviation), $\mathrm{n}=3$

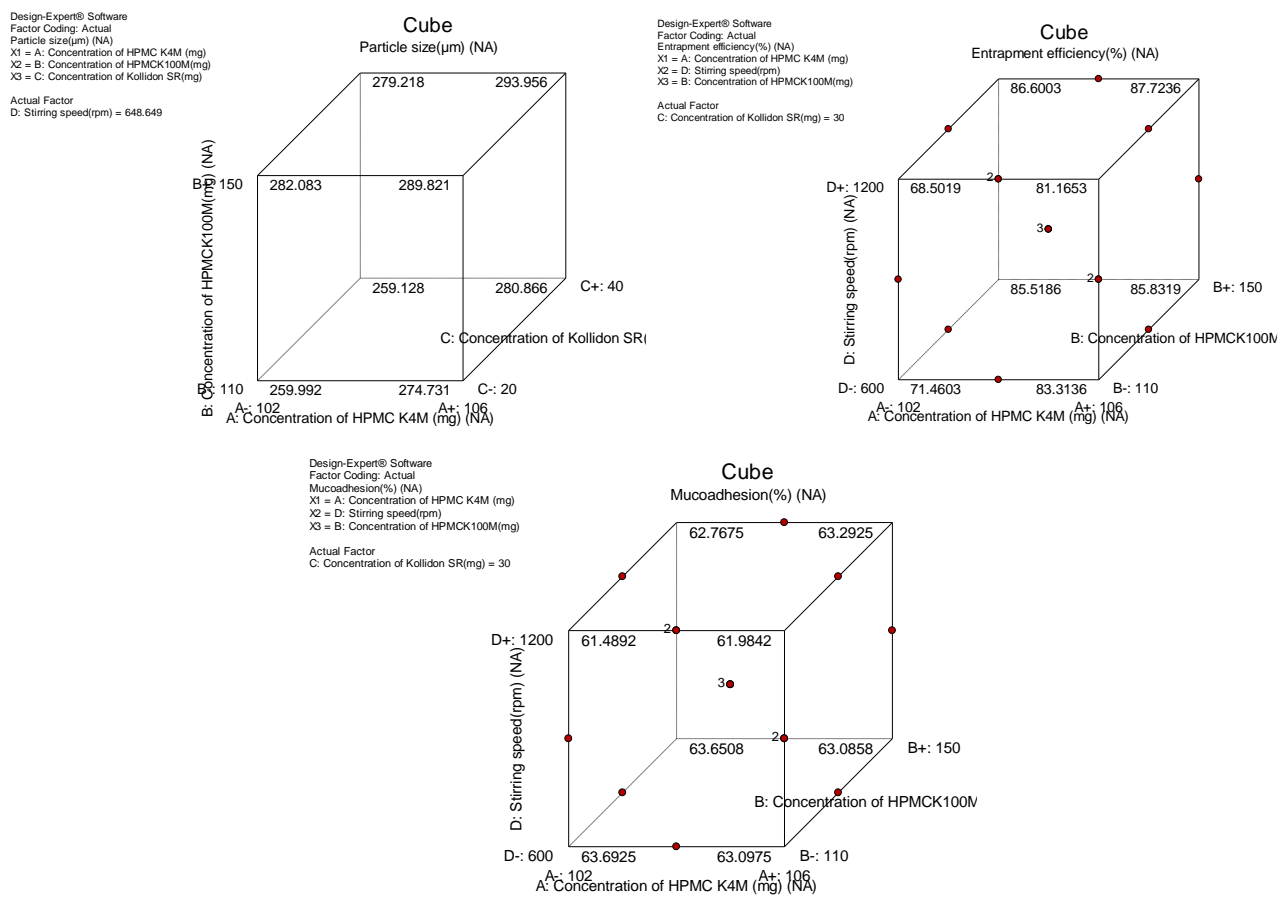

Fig. 2: Representation of cubical design spaces of factors A, B and C on corresponding responses Y1, Y2 and Y3 
Table 3: ANOVA data for quadratic model representing response Y1 (mean particle size)

\begin{tabular}{|c|c|c|c|c|c|c|}
\hline Source & Sum of squares & Df & Mean square & F value & p value & Prob $>F$ \\
\hline Model & 2435.50 & 10 & 243.55 & 6.75 & 0.0004 & \\
\hline A-Concentration of HPMC K4M (mg) & 850.08 & 1 & 850.08 & 23.57 & 0.0002 & Significant \\
\hline B-Concentration of HPMCK100M(mg) & 800.33 & 1 & 800.33 & 22.19 & 0.0002 & \\
\hline C-Concentration of Kollidon SR(mg) & 168.75 & 1 & 168.75 & 4.68 & 0.0460 & \\
\hline D-Stirring speed(rpm) & 533.33 & 1 & 533.33 & 14.78 & 0.0014 & \\
\hline $\mathrm{AB}$ & 12.25 & 1 & 12.25 & 0.34 & 0.5682 & \\
\hline AC & 12.25 & 1 & 12.25 & 0.34 & 0.5682 & \\
\hline$A D$ & 6.25 & 1 & 6.25 & 0.17 & 0.6828 & \\
\hline $\mathrm{BC}$ & 1.00 & 1 & 1.00 & 0.028 & 0.8699 & \\
\hline $\mathrm{BD}$ & 2.25 & 1 & 2.25 & 0.062 & 0.8060 & \\
\hline $\mathrm{CD}$ & 49.00 & 1 & 49.00 & 1.36 & 0.2609 & \\
\hline
\end{tabular}

\section{Entrapment efficiency of drug}

The RSM assisted and ED implemented yielded high entrapment of drug in fabricated microspheres corresponding to the following data ranging from $(68.04 \pm 0.07) \%$ to $(85.98 \pm 0.01) \%$ for all the formulation from F1 to F7. It was observed that on increase in polymer concentration, the entrapment efficiency of formulation also increased due to higher inculcations with increased polymer concentration and enhanced stirring speed. In present experimentally designed method by BBD, the two selected response were mean particle size and drug entrapment efficiency, so on implementation of selected model for both responses yielded maximum optimized drug entrapment efficiency as $85.07 \%$ for F5 formulation with maximum optimization.

Table 4: ANOVA data for quadratic model representing response Y2 (entrapment efficiency)

\begin{tabular}{|c|c|c|c|c|c|c|}
\hline Source & Sum of squares & Df & Mean square & F value & p value & Prob $>F$ \\
\hline Model & 492.97 & 10 & 49.30 & 6.54 & 0.0005 & Significant \\
\hline A-Concentration of HPMC K4M (mg) & 126.30 & 1 & 126.30 & 16.75 & 0.0008 & \\
\hline B-Concentration of HPMCK $100 \mathrm{M}(\mathrm{mg})$ & 318.79 & 1 & 318.79 & 42.29 & $<0.0001$ & \\
\hline C-Concentration of Kollidon SR(mg) & 8.94 & 1 & 8.94 & 1.19 & 0.2922 & \\
\hline D-Stirring speed(rpm) & 0.85 & 1 & 0.85 & 0.11 & 0.7409 & \\
\hline $\mathrm{AB}$ & 33.29 & 1 & 33.29 & 4.42 & 0.0518 & \\
\hline $\mathrm{AC}$ & 0.19 & 1 & 0.19 & 0.026 & 0.8747 & \\
\hline $\mathrm{AD}$ & 0.16 & 1 & 0.16 & 0.022 & 0.8846 & \\
\hline $\mathrm{BC}$ & 0.24 & 1 & 0.24 & 0.031 & 0.8620 & \\
\hline $\mathrm{BD}$ & 4.08 & 1 & 4.08 & 0.54 & 0.4726 & \\
\hline $\mathrm{CD}$ & 0.13 & 1 & 0.13 & 0.017 & 0.8987 & \\
\hline
\end{tabular}

\section{Ex-vivo mucoadhesive study}

It was observed that as the concentration of mucoadhesive polymers was increased, there was gradual increase in degree of mucoadhesion to the mucosal sample tissue, but with increase in stirring speed the mucoadhesive tendency was reduced. Hence less stirring speed with higher concentration of semi-synthetic polymers yielded enhanced mucoadhesion. The values obtained ranged from $(60.09 \pm 0.03) \%$ to $(68.07 \pm 0.05) \%$ for all the formulation from F1 to F7 with $67.03 \%$ for most optimized formulation F5.

Table 5: ANOVA data for quadratic model representing response Y3 (percent mucoadhesion)

\begin{tabular}{|c|c|c|c|c|c|c|}
\hline Source & Sum of squares & Df & Mean square & F value & p value & Prob $>$ F \\
\hline Model & 48.97 & 14 & 3.50 & 3.25 & 0.0237 & Significant \\
\hline A-Concentration of HPMC K4M (mg) & $3.675 \mathrm{E}-003$ & 1 & 3.675E-003 & $3.418 \mathrm{E}-003$ & 0.9543 & \\
\hline B-Concentration of HPMCK100M(mg) & 1.20 & 1 & 1.20 & 1.12 & 0.3110 & \\
\hline C-Concentration of Kollidon SR(mg) & 8.07 & 1 & 8.07 & 7.50 & 0.0180 & \\
\hline D-Stirring speed(rpm) & 2.99 & 1 & 2.99 & 2.78 & 0.1213 & \\
\hline $\mathrm{AB}$ & $2.250 \mathrm{E}-004$ & 1 & $2.250 \mathrm{E}-004$ & $2.092 \mathrm{E}-004$ & 0.9887 & \\
\hline $\mathrm{AC}$ & 0.43 & 1 & 0.43 & 0.40 & 0.5395 & \\
\hline $\mathrm{AD}$ & 0.30 & 1 & 0.30 & 0.28 & 0.6088 & \\
\hline $\mathrm{BC}$ & 2.77 & 1 & 2.77 & 2.58 & 0.1343 & \\
\hline BD & 0.44 & 1 & 0.44 & 0.41 & 0.5364 & \\
\hline CD & 0.76 & 1 & 0.76 & 0.70 & 0.4179 & \\
\hline $\mathrm{A}^{2}$ & 5.18 & 1 & 5.18 & 4.82 & 0.0486 & \\
\hline $\mathrm{B}^{2}$ & 27.28 & 1 & 27.28 & 25.37 & 0.0003 & \\
\hline $\mathrm{C}^{2}$ & 11.36 & 1 & 11.36 & 10.56 & 0.0070 & \\
\hline $\mathrm{D}^{2}$ & 11.22 & 1 & 11.22 & 10.43 & 0.0072 & \\
\hline
\end{tabular}

\section{In vitro drug release analysis}

The experimentally designed and optimized MFH microspheres were prepared by modified solvent-evaporation technique by incorporating semi-synthetic and synthetic polymers. The representation of drug release behavior of $\mathrm{MFH}$ fabricated microspheres revealed that all preparations from F1 to F7 were able to control the drug release from 04 to $10 \mathrm{~h}$ with percent drug release ranging from $96.08 \%$ to $91.76 \%$ respectively. F5 preparation exhibited $92.81 \%$ release profile after duration of $10 \mathrm{~h}$, hence it was selected as optimized formulation. In one study conducted by It was observed that on increasing the concentration of HPMC K100M and synthetic polymer KS, release was decreased. From among all seven 
preparations, F5 was selected as most optimized preparation representing better drug release with enhanced bioavailability. Identification of best fitting models was performed by using coefficient of determination $\left(\mathrm{R}^{2}\right)$ by placing the data of drug release kinetics. It was observed that for the formulation from F1 to F7 reached greater values for coefficient of determination $\left(R^{2}\right)$ ranging from 0.928 to 0.983 for zero order and release exponent value (n) varied from 1.502 to 2.052. The observed data of Korsmeyer-Peppas model recommended non-Fickian diffusion mechanism for fabricated MFH microspheres can be seen from table 6 .

Table 6: Drug release profile for MFH loaded microspheres by incorporating semi-synthetic and synthetic polymers

\begin{tabular}{|c|c|c|c|c|c|}
\hline \multirow[t]{2}{*}{ Formulation code } & \multicolumn{4}{|c|}{ Correlation coefficient $\left(\mathrm{R}^{2}\right)$} & \multirow[t]{2}{*}{ Release exponent (n) } \\
\hline & Zero order & First order & Higuchi model & Korsmeyer model & \\
\hline F1 & 0.928 & 0.736 & 0.718 & 0.817 & 1.502 \\
\hline F2 & 0.940 & 0.769 & 0.825 & 0.952 & 1.564 \\
\hline F3 & 0.931 & 0.878 & 0.839 & 0.840 & 1.731 \\
\hline F4 & 0.955 & 0.926 & 0.856 & 0.863 & 1.908 \\
\hline F5 & 0.979 & 0.952 & 0.898 & 0.942 & 2.052 \\
\hline F6 & 0.973 & 0.959 & 0.921 & 0.949 & 2.019 \\
\hline F7 & 0.983 & 0.968 & 0.941 & 0.957 & 1.977 \\
\hline
\end{tabular}

\section{FTIR study}

The FTIR analysis was performed by taking samples of pure drug and optimized formulation comprising of semi-synthetic and synthetic polymers inculcation. It was observed from the obtained spectra that no interaction was present between drug and polymers as no additional peaks were observed, representing stable nature of MFH in formulation, as seen in fig. 3.
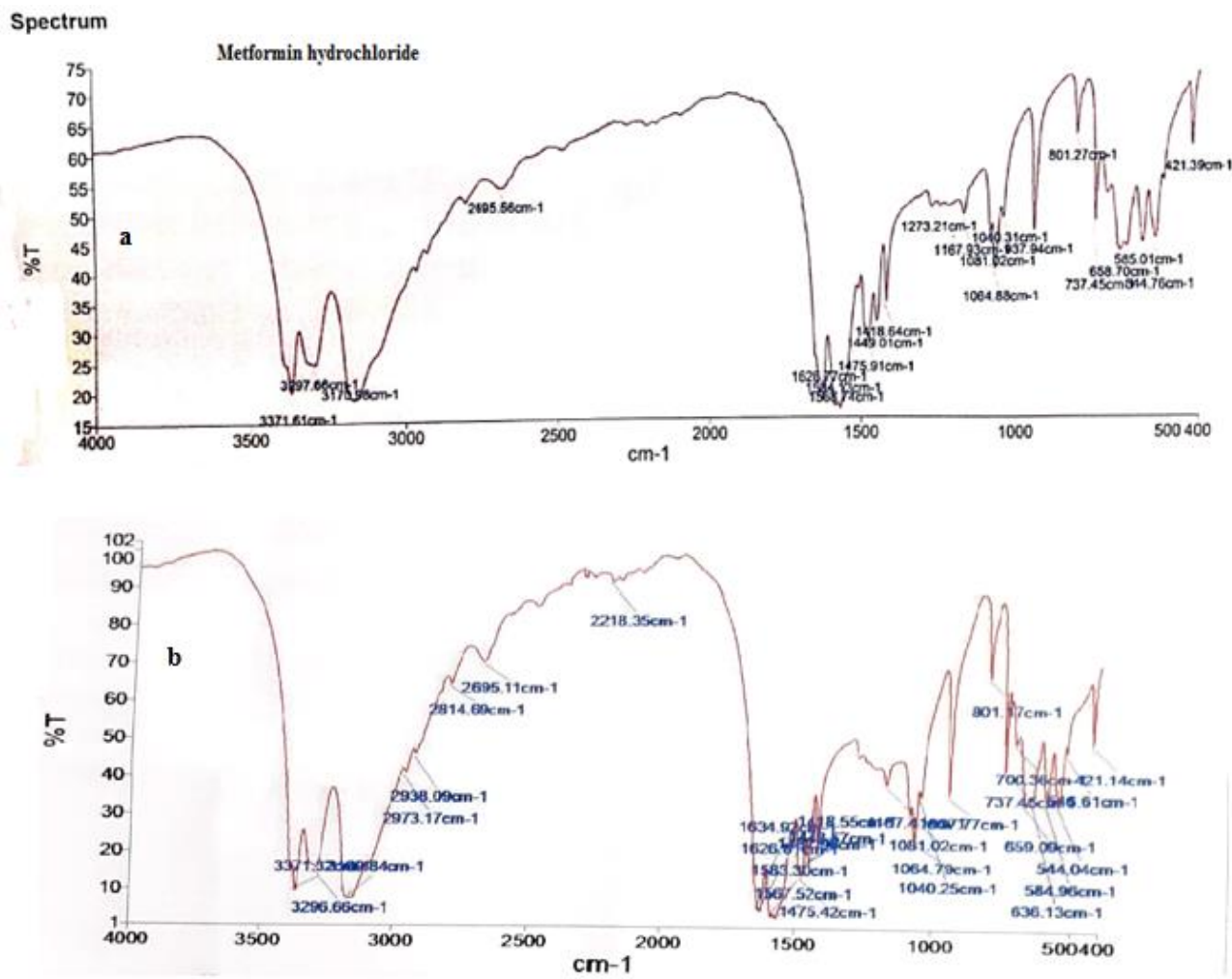

Fig. 3: IR spectra of metformin hydrochloride API (a) Metformin hydrochloride formulations (b)

\section{XRD study}

The XRD data reveals the physical state of pure MFH by showing sharp peak, representing its crystalline nature, whereas broad peaks were obtained for polymers representing their amorphous form. The results of diffractogram showed no variation in representative peak intensity height between pure MFH and the optimized formulation F5, exhibiting its crystalline nature. The observed data can be correlated with fig. 4.

\section{NMR analysis}

The $\mathrm{H}^{1} \mathrm{NMR}$ spectra obtained for optimized MFH fabricated microspheres yielded sharp singlet at $2.92 \mathrm{ppm}$ corresponding to two equivalent methyl groups, this sharp, isolated singlet was chosen as an essential criterion for quantitative determination of $\mathrm{MFH}$. At $6.71 \mathrm{ppm}$ one more singlet was observed due to remaining four protons $\left(2 \mathrm{H}\right.$ from- $\mathrm{NH}$ and $2 \mathrm{H}$ from- $\mathrm{NH}_{2}$ ), another prominent signal at $7.20 \mathrm{ppm}$ was due to the concurrent effect of two protons, one from- $\mathrm{NH}$ group and anther from $\mathrm{HCl}$, respectively. The signals obtained at $2.49 \mathrm{ppm}$ and $3.32 \mathrm{ppm}$ were due to presence of residual solvent and water of solvent from DMSO-d6, respectively. The detailed NMR spectrum of fabricated formulation can be correlated to fig. 5 and it represented that all essential chemical shifts of MFH were retained in the formulation, hence exhibiting no interaction between pure drug MFH and the selected semi-synthetic and synthetic polymers. 


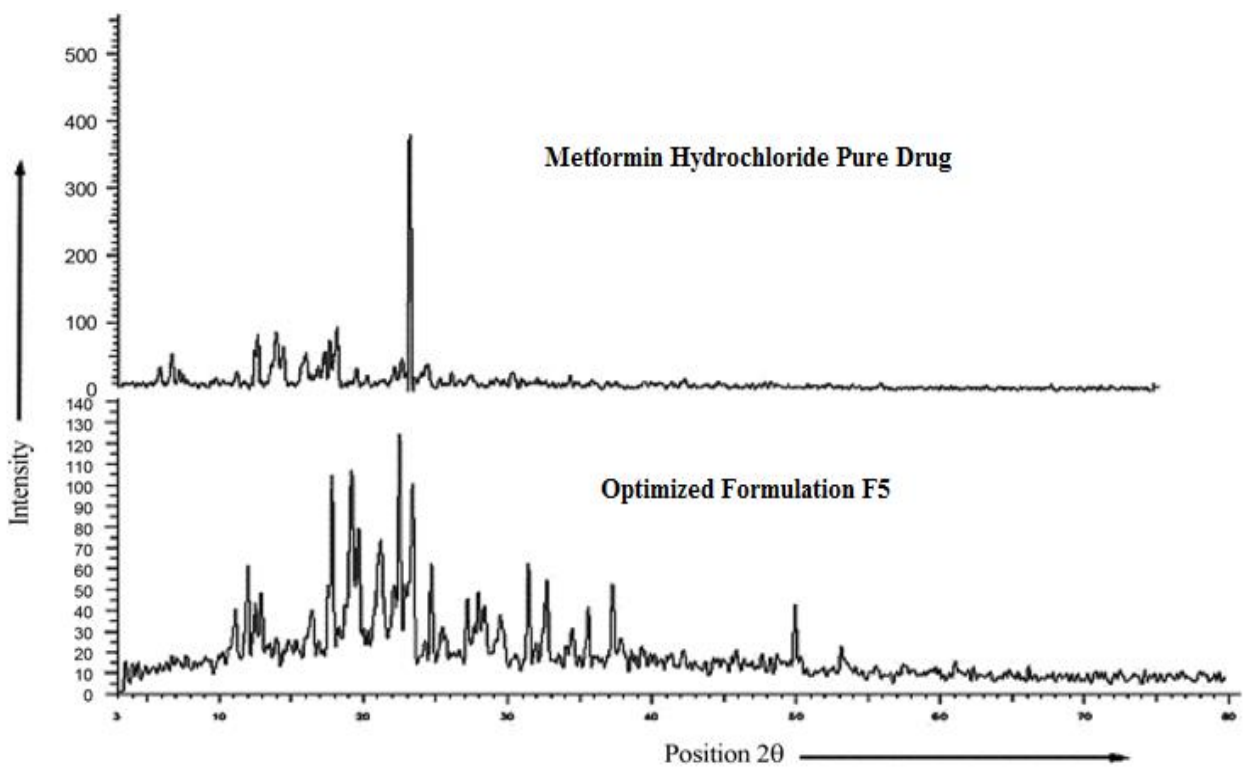

Fig. 4: XRD pattern of pure metformin hydrochloride and optimized formulation F5

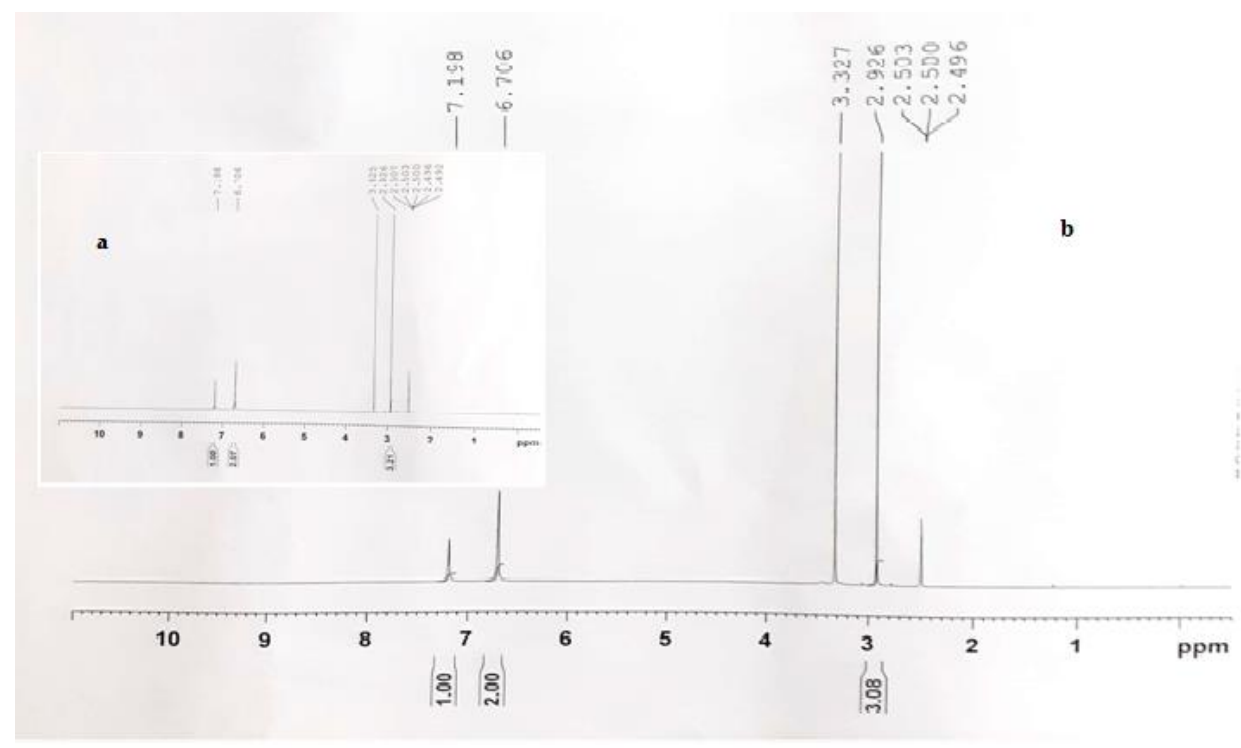

Fig. 5: NMR spectra of metformin hydrochloride API (a) Metformin hydrochloride formulations (b)

\section{CONCLUSION}

The BBD assisted optimized MFH loaded microspheres were found to have CR behavior with enhanced flow properties and improved bioavailability as compared with pure drug along with spherical microspheres fabrication with good drug entrapment efficiency and higher mucoadhesive tendency. The modified solvent evaporation technique being uncomplicated, yielded microspheres with improvement in the therapeutic window of drug with stable fabricated microspheres as observed from FTIR and $\mathrm{H}^{1}$ NMR analysis.

\section{ACKNOWLEDGEMENT}

All the authors are thankful to Aurobindo Pharmaceuticals Ltd, India, for providing the gift sample of pure drug, Metformin hydrochloride. We would also like to express our gratitude and thankfulness to Department of chemistry, Dr Babasaheb Ambedkar Marathwada University, sub-campus Osmanabad for hassle-free execution of $\mathrm{PhD}$ research work.

\section{AUTHORS CONTRIBUTIONS}

All the authors have contributed equally.

\section{CONFLICT OF INTERESTS}

All the authors declare that there is no conflict of interest by all of us.

\section{REFERENCES}

1. Hermann LS, Melander A. Biguanides, basic aspects and clinical use in international textbook of diabetes mellitus. KG Alberti. editors. Wiley: New York; 1992. p. 772-95.

2. Dunn JC, Peters DH. Metformin: a review of its pharmacological properties and therapeutic use in non-insulin-dependent diabetes mellitus. Drugs 1995;49:721-49.

3. Wiley A. Insulin and oral hypoglycemic drugs. Williams DA, Lemke TL. editors. Foyes Principle of medicinal chemistry: New York; 2002. p. 641-8.

4. Chakra BK, Karan S, Das B, Debnath S, Chatterjee TK. A controlled release microsphere formulation of an anti-diabetic 
drug and characterization of the microsphere. Int J Pharm Pharm Sci 2018;10:30-8.

5. Hundal RS, Inzucchi SE. Metformin: New understandings, new uses. Drugs 2003;63:1879-94.

6. Kidson W. Polycystic ovary syndrome: a new direction in treatment. Med J Aust 1998;169:537-40.

7. Sahra IB, Brustel YLM, Tanti JF, Bost F. Metformin in cancer therapy: a new perspective for an old antidiabetic drug. Mol Cancer Ther 2010;9:1092-9.

8. Esteghamati A, Eskandari D, Mirmiranpour H, Noshad S, Mousavizadeh M, Hedayati $\mathrm{M}$, et al. Effects of metformin on markers of oxidative stress and antioxidant reserve in patients with newly diagnosed type 2 diabetes: a randomized clinical trial. Clin Nutr 2013;32:179-85.

9. Roussel R, Travert F, Pasquet B. Reduction of atherothrombosis for continued health registry investigators: metformin use and mortality among patients with diabetes and atherothrombosis. Arch Intern Med 2010;170:1892-9.

10. Rangel ES, Inzucchi SE. Metformin: clinical use in type 2 diabetes. Diabetologia 2017;60:1586-93.

11. Scarpello JH, Howlett HC. Metformin therapy and clinical uses. Diab Vasc Dis Res 2008;5:157-67.

12. Wilcock C, Bailey CJ. Sites of metformin-stimulated glucose metabolism. Biochem Pharmacol 1990;39:1831-4.

13. Laurence LB, Johns L, Keith LP. $11^{\text {th }}$ edition Goodman and gillman: the pharmacological basis of therapeutics; 2007.

14. Siepmann J, Peppas NA. Modeling of drug release from delivery systems based on hydroxypropyl methylcellulose (HPMC). Adv Drug Delivery Rev 2012;64:163-74.

15. Ige PP, Gattani S. Development of low density microspheres of metformin hydrochloride using ethyl cellulose and HPMC K4M: in vitro and in vivo characterization. Polymer Plast Tech Eng 2012;51:1537-44.

16. Chen C, Han CH, Sweeney M, Cowles VE. Pharmacokinetics, efficacy, and tolerability of a once daily gastroretentive dosage form of gabapentin for the treatment of postherpetic neuralgia. J Pharm Sci 2013;102:1155-64.

17. Jagtap P, Tagad R, Shendge R. A brief review on Kollidon. J Drug Delivery Ther 2019;9:493-500.

18. Sakr W, Alanazi F, Sakr A. Effect of kollidon $® S R$ on the release of albuterol sulphate from matrix tablets. Saudi Pharm ] 2011;19:19-27.

19. Sarkar D, Nandi G, Changder A, Hudati P, Sarkar S, Ghosh LK Sustained release gastroretentive tablet of metformin hydrochloride based on poly (acrylic acid)-grafted-gellan. Int J Biol Macromol 2017;96:137-48.

20. Russo E, Selmin F, Baldassari S, Gennari CGM, Caviglioli G, Cilurzo $\mathrm{F}$, et al. A focus on mucoadhesive polymers and their application in buccal dosage forms. J Drug Delivery Sci Technol 2016;32:113-25

21. Menchicchi B, Fuenzalida JP, Hensel A, Swamy MJ, David L, Rochas $\mathrm{C}$, et al. Biophysical analysis of the molecular interactions between polysaccharides and mucin. Biomacromolecules 2015;16:924-35.

22. Karna S, Agrawal VK, Chaturvedi S, Alim M. Swellable and floating gastroretentive formulation for sustained delivery of metformin HCL. Int J Pharm Sci Res 2016;7:1590-602.

23. Quazi MA, Khanam N, Tigote RM. Fabrication and characterization of metformin hydrochloride loaded microspheres by incorporating natural and synthetic polymers for comparative analysis. Int J Pharm Sci Res 2020;11:6539-49.

24. Alam MI, Siddiqui AR, Khanam N, Kamaruddin SJ. A multivariate quantification of box-behnken design assisted method development and validation of dextromethorphan hydrobromide and desloratadine simultaneously by reverse-phase HPLC in inhouse syrup formulation. J Sep Sci 2020;43:1-10.

25. Deshmukh RK, Naik JB. Aceclofenac microspheres, quality by design approach. Mater Sci Eng C Mater Biol Appl 2014;36:320-8.

26. Khanam N, Alam MI, Ali QI, Siddiqui AR. A review on optimization of drug delivery system with experimental designs. Int J Appl Pharm 2018;10:7-12.

27. Maulvi FA, Thakkar VT, Soni TG, Gandhi TR. Optimization of aceclofenac solid dispersion using box-behnken design: in vitro and in vivo evaluation. Curr Drug Delivery 2014;11:380-91.

28. Khanam N, Alam MI, Sachan AK, Gangwar SS, Anand C. Design and characterization of mucoadhesive microspheres of novel NSAID drug using algino-eudragit RS 100 system. Der Pharm Sin 2011;2:182-91

29. Khanam N, Alam IM, Sachan KA, Gangwar S. Fabrication and evaluation of propranolol hydrochloride loaded microspheres by ionic-gelation technique. Der Pharm Lett 2012;4:815-20.

30. Ige $\mathrm{PP}$, Gattani SG. Design and in vitro and in vivo characterization of mucoadhesive matrix pellets of metformin hydrochloride for oral controlled release: a technical note. Arch Pharm Res 2012;35:487-98.

31. Kesharvani S, Jaiswal PK, Mukerjee A, Singh AK. Formulation and evaluation of metformin hydrochloride loaded floating microspheres. Int J Pharm Pharm Sci 2020;12:74-82. 